\title{
Serum level of interleukin-15 in active alopecia areata patients and its relation to age, sex, and disease severity
}

\author{
Magdy Abd El Aziz Ragab¹, Eman Mohamed Hassan¹, Dalia Abd EL Moaty El Niely², Mai Mahmoud Mohamed ${ }^{1}$ \\ ${ }^{1}$ Department of Dermatology, Venereology and Andrology, Faculty of Medicine, Alexandria University, Alexandria, Egypt \\ ${ }^{2}$ Department of Clinical and Chemical Pathology, Faculty of Medicine, Alexandria University, Alexandria, Egypt \\ Adv Dermatol Allergol 2020; XXXVII (6): 904-908 \\ DOI: https://doi.org/10.5114/ada.2020.102103
}

\begin{abstract}
Introduction: Autoimmune mechanisms with evident genetic background are the main components of alopecia areata (AA) pathogenesis. Interleukin 15 (IL-15) is considered as an important signalling cytokine. Its disordered expression has been linked to inflammatory autoimmune disorders.

Aim: The present study aimed to evaluate serum IL-15 in active AA patients and to assess its association with patients' sex, age, and disease severity.

Material and methods: IL-15 serum level was measured in 40 patients with active alopecia areata and 20 healthy controls using the ELISA technique. The severity of hair loss was assessed in accordance with the Severity of Alopecia Tool (SALT).

Results: A significantly higher serum level of IL-15 in AA patients than in controls was detected $(p<0.001)$. A significant positive correlation was detected between the SALT score and IL-15 serum level $\left(r_{s}=0.433, p=0.005\right)$. No significant correlation between age of the patients and the serum level of IL-15 was observed $\left(r_{s}=0.224\right.$, $p=0.164)$. No significant difference in IL-15 serum level regarding patients' sex, history of disease recurrence, or family history of AA was noted.

Conclusions: The elevated serum level of IL-15 in active AA patients might reflect its role in disease pathogenesis as a key signalling cytokine. Its level is correlated with disease severity. However, IL-15 is not influenced by patients' gender or age.
\end{abstract}

Key words: alopecia areata, interleukin-15, alopecia severity.

\section{Introduction}

Alopecia areata (AA) is an autoimmune disease targeting the anagen hair follicle [1]. It has a genetic background based on genome-wide association studies as well as familial clustering of cases [2]. This autoimmune process results from disruption of follicular immune privilege either starting as a local disturbance in the hair follicle itself or, according to a more accepted theory, as a result of the dysregulated immune system [3].

There is abnormal upregulation of major histocompatibility-I (MHC-I) and UL16 binding protein 3 (ULBP3) molecules on the hair follicles which are considered as ligands for abnormal infiltration of the cytotoxic cluster of differentiation 8-positive (CD8+)NK group 2D-positive (NKG2D+) effector memory T-cells [4]. Together with defective natural killer (NK) cells inhibition, all these factors make hair follicle self-antigens susceptible to be expressed to the abnormal immune response [5]. Other immune pathways act as important steps in immune privilege collapse including the neuroendocrine pathway and Thelper 17 involvement [3]. Concurrently, several cytokines including interleukin (IL)-2, IL-7, tumor necrosis factor- $\alpha$ (TNF- $\alpha$ ), and interferon- $\gamma$ (IFN- $\gamma$ ) are upregulated in cases of alopecia areata with further promotion of T-cell recruitment [6].

Interleukin 15 (IL-15) is well known to promote lymphocytic development and it is now suggested to play a key role in some autoimmune diseases such as multiple sclerosis, rheumatoid arthritis, ulcerative colitis, and celiac disease. However, its actual mechanism of involvement is still being clarified [7]. IL-15 inhibits the well-known selftolerance that, mediated by activation-induced cell death, promotes maintenance of CD8+ memory $T$ cells with in-

Address for correspondence: Dr. Eman Mohamed Hassan, Department of Dermatology, Venereology and Andrology, Faculty of Medicine, Alexandria University, El Azarita 21521, Alexandria, Egypt, phone: +2 01002217040, e-mail: dr_eman_mh@yahoo.com Received: 29.03.2019, accepted: 23.04.2019. 
duction of some cytokines involved in autoimmune processes such as TNF- $\alpha$ and IL-1 $\beta[8]$.

As regards its involvement in dermatological diseases, IL-15 was shown to be associated with psoriasis, sarcoidosis, systemic lupus, and graft versus host disease. However, IL-15 involvement in alopecia areata is still under investigation [7].

\section{Aim}

The aim of the present study is to assess the association of IL-15 with active alopecia areata and its relation to age, sex, and disease severity.

\section{Material and methods}

The present study was conducted at the hair outpatient clinic of the main university hospital, Faculty of Medicine, Alexandria University. It was approved by the local ethics committee in accordance with the Declaration of Helsinki of 1975.

Forty patients with active alopecia areata were enrolled into the study and twenty healthy control subjects were included. Written informed consent was obtained from all participants. All patients were subjected to full history taking (including age, sex, disease duration, disease onset, and course), medical history, drug history and family history. Exclusion criteria of the present study included acute or chronic inflammation, autoimmune diseases, history of cancer, pregnancy and lactation [7]. Patients on topical treatment for alopecia areata within the past month or systemic treatment within the past 3 months were excluded.

The patients were diagnosed to have active alopecia areata by history of active hair loss within the past 6 months [9], positive pull test [10], exclamation mark hair seen clinically at the periphery of the lesions [11] and trichoscopic examinations showing black dots, broken hair and exclamation marks [12]. The extent of the scalp involvement was further evaluated using the Severity Alopecia Tool (SALT) $[13,14]$.

\section{Evaluation of IL-15 serum level}

Five $\mathrm{ml}$ of venous blood was collected from the patients and the healthy individuals. The serum was allowed to clot for 30 min using a serum separator tube before centrifugation for $15 \mathrm{~min}$ and stored at $-80^{\circ} \mathrm{C}$ until samples of patients and control groups were assayed in one run. Samples were assessed according to the manufacturer's instructions. Serum levels of IL-15 were quantitated with a commercially available enzyme linked immunosorbent assay (ELISA) kit (EIAab Science Co. Ltd., Wuhan, China, E0061h).

\section{Statistical analysis}

Data were fed to the computer and analysed using IBM SPSS software package version 20.0. (IBM Corp., Armonk, NY, USA). Qualitative data were described using number and percent. Quantitative data were described using range (minimum and maximum), mean, standard deviation and median. The $\chi^{2}$ test was used for categorical variables, while Student $t$-test for normally quantitative variables. Mann Whitney test was used for abnormally quantitative variables. Spearman coefficient was used to correlate between two abnormally quantitative variables. Results were judged at the 5\% level.

\section{Results}

In the present study, the forty patients with active alopecia areata of the scalp reported that their duration of the disease ranged from 2 to 6 months.

The age mean \pm SD of the patients was $26.95 \pm 12.54$ years (range: $5-52$ years) and of the controls was 33.7 \pm 17.8 years with $p=0.0140$ (range: $5-52$ years, $10-62$ years, respectively). Of the 40 patients, 26 (65\%) were males and 14 (35\%) were females, while $12(60 \%)$ of the controls were males and $8(40 \%)$ of them were females $(p=0.705)$.

The history of recurrence was reported in 10 (25\%) patients, stressful event associations were reported in 19 (47.5\%) patients, whereas a positive family history of alopecia areata in first-degree relatives was detected in 2 (5\%) patients. Nail affection was not detected in association with alopecia areata patients in the current study, whereas affection of the beard was reported in 14 (35\%) patients.

In patients, the serum level of IL-15 was $13.20-41 \mathrm{pg} /$ $\mathrm{ml}($ mean \pm SD: $22.80 \pm 5.99 \mathrm{pg} / \mathrm{ml})$, while in the controls was $0-5.9 \mathrm{pg} / \mathrm{ml}$ (mean \pm SD: $0.3 \pm 1.32 \mathrm{pg} / \mathrm{ml})$. A statistically significant higher level of IL-15 was observed in patients than in controls $(p<0.001)$ (Table 1$)$.

As regards the SALT score, mean \pm SD was 9.67 \pm 22.53 with a significant positive correlation detected between the SALT score and IL-15 serum level $\left(r_{s}=0.433\right.$, $p=0.005$ ) (Figure 1).

In the patients group; IL-15 level (mean \pm SD: 22.8 $\pm 6.3 \mathrm{pg} / \mathrm{ml}$ ) in 26 males and (mean \pm SD: $22.7 \pm 5.6 \mathrm{pg} / \mathrm{ml}$ ) in 14 females with no significant difference in the IL-15 serum level in relation to the gender $(p=0.958)$ (Table 2). The patients' age was 5-52 years old; 19 (47.5\%) patients $\leq 25$ years and 21 (52.5\%) patients $\leq 25$ years. IL-15 level shows no significant difference between both previous groups of age (mean \pm SD: $21.4 \pm 3.8 \mathrm{pg} / \mathrm{ml}$, mean \pm SD: $24.1 \pm 7.3 \mathrm{pg} / \mathrm{ml}$ respectively) ( $p=0.142)$ (Table 3$)$. There was no significant correlation between the age of the patients and the serum level of IL-15 $\left(r_{s}=0.224, p=0.164\right)$.

The IL-15 level showed no significant difference between those cases presented with alopecia areata for the first time and those with a history of recurrence ( $p=$ 0.510). No significant difference of the IL-15 level between cases with a positive family history of AA and cases lacking any family history of previous AA ( $p=0.203)$ was observed. 
Table 1. Comparison between the two studied groups according to interleukin-15 levels

\begin{tabular}{lccc}
\hline $\begin{array}{l}\text { Interleukin-15 } \\
\text { level }[\mathrm{pg} / \mathrm{ml}]\end{array}$ & $\begin{array}{c}\text { Patients } \\
(n=40)\end{array}$ & $\begin{array}{c}\text { Controls } \\
(n=20)\end{array}$ & $P$-value \\
\cline { 1 - 3 } Min.-max. & $13.20-41.0$ & $0.0-5.9$ & $<0.001^{\mathrm{a}}$ \\
\cline { 1 - 3 } Mean \pm SD & $22.80 \pm 5.99$ & $0.3 \pm 1.32$ & \\
\cline { 1 - 3 } Median & 22.15 & 0.0 & \\
\hline
\end{tabular}

aMann-Whitney test. Statistically significant at $p<0.05$.

Table 2. Relation between sex and interleukin-15 level in the patients group $(n=40)$

\begin{tabular}{lcccc}
\hline $\begin{array}{l}\text { Interleukin-15 } \\
\text { level }[\mathrm{pg} / \mathrm{ml}]\end{array}$ & \multicolumn{2}{c}{ Sex } & $\begin{array}{c}\text { Test of } \\
\text { significance }\end{array}$ & $P$-value \\
\cline { 2 - 3 } & $\begin{array}{c}\text { Male } \\
(n=26)\end{array}$ & $\begin{array}{c}\text { Female } \\
(n=14)\end{array}$ & & \\
\cline { 1 - 3 } Min.-max. & $14.9-41.0$ & $13.2-34.9$ & & \\
\cline { 1 - 3 } Mean \pm SD & $22.8 \pm 6.3$ & $22.7 \pm 5.6$ & & 0.958 \\
\cline { 1 - 3 } Median & 22.3 & 21.95 & & \\
\hline
\end{tabular}

t, $p$-t and $p$-values for Student $t$-test for comparison between the two groups.

Table 3. Relation between age and interleukin-15 level in the patients group $(n=40)$

\begin{tabular}{lcccc}
\hline $\begin{array}{l}\text { Interleukin-15 } \\
\text { level }[\mathrm{pg} / \mathrm{ml}]\end{array}$ & \multicolumn{2}{c}{ Age [years] } & $\begin{array}{c}\text { Test of } \\
\text { significance }\end{array}$ & $P$-value \\
\cline { 2 - 3 } & $\begin{array}{c}\leq 25 \\
(n=19)\end{array}$ & $\begin{array}{c}>25 \\
(n=21)\end{array}$ & & \\
\cline { 1 - 3 } Min.-max. & $13.2-29.4$ & $14.9-41.0$ & & \\
\cline { 1 - 3 } Mean \pm SD & $21.4 \pm 3.8$ & $24.1 \pm 7.3$ & & 0.142 \\
\cline { 1 - 3 } Median & 21.2 & 23.1 & & \\
\hline
\end{tabular}

t, $p$-t and $p$-values for Student $t$-test for comparison between the two groups.

\section{Discussion}

Based on the present results which reported a higher serum level of IL-15 in AA patients than in controls and on the previous few studies on IL-15 at the tissue level of both animal and human alopecia areata, the role of IL-15 in AA pathogenesis should be clarified.

The concept of the autoimmune phenomenon explaining the collapse of immune privilege of hair follicle in alopecia areata is supported by its high association with other immune-mediated disorders such as thyroiditis and vitiligo and by its response to immune-modifying therapies $[15,16]$. An intriguing finding that immune response in AA is of heterogeneous subtype was reported and gene expression studies detected mixed immune response of both Th1 and Th2 in the lesional skin of AA [17]. In addition, identification of pathogenic NKG2D+CD8+ cytotoxic T-cells leads to better understanding of the cytokine milieu involved in AA pathogenesis [18].

IL-15 is a proinflammatory cytokine that has a role in development, activation and survival of NK cells and in peripheral T-cell homeostasis [19]. It induces survival of CD8+ memory T-cell including autoreactive memory Tcell. It can stimulate the expression of TNF- $\alpha$ and IL-1 [8].

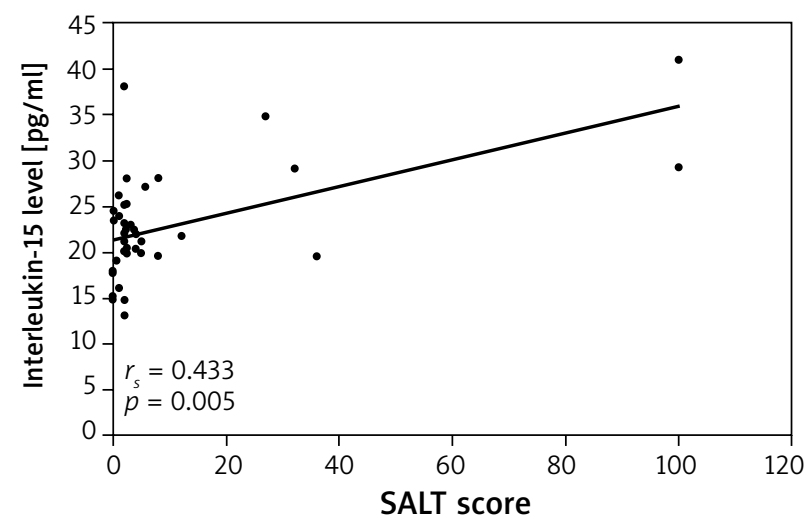

Figure 1. Correlation between SALT score with interleukin-15 level in patients $(\mathrm{pg} / \mathrm{ml})(n=40)$

These facts suggest its role in the autoimmune process. A previous report showed that IL-15 or IL-15R $\alpha$ genetically deficient mice do not manifest autoimmune disorders [8].

IL-15 has a heterotrimeric receptor which consists of 3 subunits: first unique IL-15R $\alpha$ subunit, second IL-2/IL-15 $\beta$ receptor which is shared with $\mathrm{IL}-2$, and the third common cytokine receptor $\gamma$ chain which is shared by IL-2, IL-4, IL-7, IL-9 and IL-21 [8]. By understanding the previous effects of IL-15 and its sharing capacity with other cytokines for the same receptors paves the way to be considered as an important modulator of the immune process. It is reported to be involved in some autoimmune diseases; however its role in AA is still not fully elucidated.

Gene expression signatures of $\gamma c$ cytokines and their receptors including transcript for IL-15 was identified in lesional skin of alopecia areata in both humans and mice. In addition, immunofluorescence detection of IL-15 and its unique IL-15 $\alpha$ receptor showed their upregulation in AA hair follicle and expression of IL-15R $\beta$ on infiltrating human CD8+ T-cell. Systemic administration of IL-15R antibodies via intraperitoneal route blocked alopecia areata development [20, 21]. These findings were further supported by other studies [22, 23].

It was found that IL-15 could be expressed by stressed keratinocytes or by activated immune cells [3]. As an additional proof of IL-15 in AA, it was found to limit the inhibitory capacity of T-regulatory cells and it can prime resting NK cells to kill by promoting the expression of NKG2D which is considered a key for promotion of AA pathogenesis [24, 25].

In the lesional skin of AA, CD8+NKG2D+ cells produced IFN- $\gamma$ which further induces IL-15 and IL-15R $\alpha$ by hair follicle that proved to act as feed forward loop which promotes autoimmune response [21].

The receptors of Janus kinase-signal transducer and activator of transcription (JAK-STAT) signalling pathway bind to specific ligands and then phosphorylate its tyrosine component with further activation of STAT component, and translocate to the nucleus to promote gene expression. Several cytokines are now proved to activate 
this pathway, especially $\gamma$ c cytokines including IL-15 [2, 26]. Disturbed JAK-STAT components were reported to be associated with autoimmune disorders [2, 27]. It was postulated that activation of JAK-STAT signalling via IL-15 mediates CD8+NKG2D+ cell activation [2]. JAK1, JAK2, and especially JAK3 were overexpressed in the lesional skin of AA [28]. This point of view has been proved by Xing et al. to further support the role of IFN- $\gamma$ and $\gamma$ c cytokines including IL-15 for the downstream signalling pathway via JAK components [21]. The emerging role of JAK inhibitors in treatment of AA via targeting IL-15 is recently discussed in several studies using both topical and systemic route in AA cases with preliminary promising results [2, 26, 29].

In autoimmune diseases, an increased expression of inflammatory mediators such as IFN- $\gamma$, TNF- $\alpha$ and IL-1 are known to increase IL-15 expression [7]. Its increased expression can be found in autoimmune diseases at the tissue level such as in celiac disease and dermatitis or at the serum level as in Behçet's disease and graft versus host disease or at both levels as in multiple sclerosis and systemic lupus erythematosus [7].

In the present study, the IL-15 serum level was significantly higher in AA patients in comparison to the controls. Previous studies evaluated important cytokines in AA pathogenesis such as IFN- $\gamma$, TNF- $\alpha$, IL-2, and IL-12 serum and their levels were found to be elevated in AA patients [30, 31]. In the current study, serum IL-15 was found to be positively correlated with SALT score. Similarly, IFN- $\gamma$, IL-2, and TNF- $\alpha$ serum levels were reported to be associated with disease severity [30, 31]. On the other hand, serum IL-15 was found to be associated with disease severity in other autoimmune diseases such as SLE, type I diabetes, and early arthritis [32-34]. Similar to the present study, it has been recently reported that the IL-15 level was higher in patients and also it was positively correlated with SALT score [35]. However, the present work targeted the active form of alopecia areata based on clinical and trichoscopic criteria which might point to the role of IL-15 in the active stage of the disease.

In this work, additional relations to patients' sex and age were evaluated. Serum IL-15 was not related to patients' gender. Although autoimmune disorders are in general affected by sex of the patients [36], but no sex dominance has been reported in cases of AA as in the present work. Similarly, IL-15 serum level was not correlated with patients' age as in cases of early arthritis [36].

Serum IL-15 was not related to the history of disease recurrence or family history of $A A$. It should be noted that the age of the patients, gender, duration of AA did not affect patients' response to JAK inhibitors which target IL-15 [29]. These findings might indirectly support our findings.

\section{Conclusions}

The elevated serum level of IL-15 in patients with active AA might suggest its role as an important signalling cytokine in the pathogenesis of AA. Its level is influenced by disease severity which might reflect disease prognosis. Further studies on a larger sample size are needed to clarify the role of IL-15 in AA. Recent studies on JAK inhibitors, either a systemic or topical form, targeting pathogenic molecules including IL-15 are now gaining interest in order to prove its safety and efficacy in treatment of AA.

\section{Conflict of interest}

The authors declare no conflict of interest.

\section{References}

1. Gilhar A, Paus R, Kalish RS. Lymphocytes, neuropeptides, and genes involved in alopecia areata. J Clin Invest 2007; 117: 2019-27.

2. Triyangkulsri K, Suchonwanit P. Role of janus kinase inhibitors in the treatment of alopecia areata. Drug Des Devel Ther 2018; 12: 2323-35.

3. Rajabi F, Drake LA, Senna MM, et al. Alopecia areata: a review of disease pathogenesis. Br J Dermatol 2018; 179: 1033-48.

4. Gilhar A, Schrum AG, Etzioni A, et al. Alopecia areata: animal models illuminate autoimmune pathogenesis and novel immunotherapeutic strategies. Autoimmun Rev 2016; 15: 726-35.

5. Ito T, Ito N, Saatoff M, et al. Maintenance of hair follicle immune privilege is linked to prevention of NK cell attack. J Invest Dermatol 2008; 128: 1196-206.

6. Gregoriou S, Papafragkaki D, Kontochristopoulos G, et al. Cytokines and other mediators in alopecia areata. Mediators Inflamm 2010; 2010: 928030.

7. Anthony SM, Schluns KS. Emerging roles for IL-15 in the activation and function of T-cells during immune stimulation. Res Rep Biol 2015; 6: 25-37.

8. Waldmann TA. Targeting the interleukin-15/interleukin-15 receptor system in inflammatory autoimmune diseases. Arthritis Res Ther 2004; 6: 174-7.

9. Ono S, Otsuka A, Yamamoto Y, et al. Serum granulysin as a possible key marker of the activity of alopecia areata. J Dermatol Sci 2013; 73: 74-9.

10. Werner B, Mulinari-Brenner F. Clinical and histological challenge in the differential diagnosis of diffuse alopecia: female androgenetic alopecia, telogen effluvium and alopecia areata - part II. An Bras Dermatol 2012; 87: 884-90.

11. Pratt CH, King Jr LE, Messenger AG, et al. Alopecia areata. Nat Rev Dis Primers 2017; 3: 17011.

12. Hegde SP, Naveen KN, Athanikar SB, et al. Clinical and dermatoscopic patterns of alopecia areata: a tertiary care centre experience. Int J Trichology 2013; 5: 132-6.

13. Olsen E, Hordinsky M, McDonald-Hull S, et al. Alopecia areata investigational assessment guidelines. National Alopecia Areata Foundation. J Am Acad Dermatol 1999; 40: 242-6.

14. Olsen EA, Hordinsky MK, Price VH, et al. Alopecia areata investigational assessment guidelines - part II. National Alopecia Areata Foundation. J Am Acad Dermatol 2004; 51: 440-7.

15. Goh C, Finkel M, Christos P, et al. Profile of 513 patients with alopecia areata: associations of disease subtypes with atopy, autoimmune disease and positive family history. J Eur Acad Dermatol Venereol 2006; 20: 1055-60.

16. Gordon KA, Tosti A. Alopecia: evaluation and treatment. Clin Cosmet Investig Dermatol 2011; 4: 101-6. 
17. Suarez-Farinas M, Ungar B, Noda S, et al. Alopecia areata profiling shows Th1, Th2, and IL-23 cytokine activation without parallel Th17/Th22 skewing. J Allergy Clin Immunol 2015; 136: $1277-87$.

18. Wang ECE, Christiano AM. The changing landscape of alopecia areata: the translational landscape. Adv Ther 2017; 34: 1586-93.

19. O'Shea JJ. Targeting the Jak/STAT pathway for immunosuppression. Ann Rheum Dis 2004; 63 (Suppl II): ii67-71.

20. Brajac I, Gruber F, Petrovecki M, et al. Interleukin-2 receptor $\alpha$-chain expression in patients with alopecia areata. Acta Dermatovenerol Croat 2004; 12: 154-6.

21. Xing L, Dai Z, Jabbari A, et al. Alopecia areata is driven by cytotoxic T lymphocytes and is reversed by JAK inhibition. Nat Med 2014; 20: 1043-9.

22. Fuentes-Duculan J, Gulati N, Bonifacio KM, et al. Biomarkers of alopecia areata disease activity and response to corticosteroid treatment. Exp Dermatol 2016; 25: 282-6.

23. Petukhova L, Duvic M, Hordinsky M, et al. Genome-wide association study in alopecia areata implicates both innate and adaptive immunity. Nature 2010; 466: 113-7.

24. Jabri B, Abadie V. IL-15 functions as a danger signal to regulate tissue-resident T cells and tissue destruction. Nat Rev Immunol 2015; 15: 771-83.

25. Meresse B, Chen Z, Ciszewski C, et al. Coordinated induction by IL15 of a TCR independent NKG2D signalling pathway converts CTL into lymphokine-activated killer cells in celiac disease. Immunity 2004; 21: 357-66.

26. Divito SJ, Kupper TS. Inhibiting Janus kinases to treat alopecia areata. Nature Med 2015; 20: 989-90.

27. Macchi P, Villa A, Giliani S, et al. Mutations of Jak-3 gene in patients with autosomal severe combined immune deficiency (SCID). Nature 1995; 377: 65-8.

28. Alves de Medeiros AK, Speeckaert R, Desmet E, et al. JAK3 as an emerging target for topical treatment of inflammatory skin diseases. PLoS One 2016; 11: e0164080.

29. Phan K, Sebaratnam DF. JAK inhibitors for alopecia areata: a systematic review and meta-analysis. J Eur Acad Dermatol Venereol 2019; 33: 850-6.

30. El-Morsy EH, Eid AA, Ghoneim H, et al. Serum level of interleukin-17A in patients with alopecia areata and its relationshipto age. Int J Dermatol 2016; 55: 869-74.

31. Atwa MA, Youssef N, Bayoumy NM. T-helper 17 cytokines (interleukins 17, 21, 22, and 6, and tumor necrosis factoralpha) in patients with alopecia areata: association with clinical type and severity. Int I Dermatol 2016; 55: 666-72.

32. Lin SJ, Kuo ML, Hsiao HS, et al. Activating and inhibitory receptors on natural killer cells in patients with systemic lupus erythematosis-regulation with interleukin-15. PLoS One 2017; 12: e0186223.

33. Kuczyński S, Winiarska H, Abramczyk M, et al. IL-15 is elevated in serum patients with type 1 diabetes mellitus. Diabetes Res Clin Pract 2005; 69: 231-6.

34. González-Álvaro I, Ortiz AM, Alvaro-Gracia JM, et al. Interleukin 15 levels in serum may predict a severe disease course in patients with early arthritis. PLoS One 2011; 6: e29492.

35. Ebrahim AA, Salem RM, El Fallah AA, et al. serum interleukin-15 is a marker of alopecia areata severity. Int J Trichol 2019; 11: 26-30.

36. Wasserman D, Guzman-Sanchez DA, Scott K, et al. Alopecia areata. Int J Dermatol 2007; 46: 121-31. 